\title{
Modern Contraceptive Utilization and Its Associated Factors Among Women Beggars in Bahir Dar Town, North West Ethiopia
}

\author{
Addisu Engdaw \\ Addis Ababa Health Office, Addis Ababa, Ethiopia \\ Email address: \\ Addisuen1@Gmail.Com \\ To cite this article: \\ Addisu Engdaw. Modern Contraceptive Utilization and Its Associated Factors Among Women Beggars in Bahir Dar Town, North West \\ Ethiopia. American Journal of Health Research. Vol. 8, No. 4, 2020, pp. 49-59. doi: 10.11648/j.ajhr.20200804.11
}

Received: April 5, 2020; Accepted: June 1, 2020; Published: July 4, 2020

\begin{abstract}
In Ethiopia the health extension packages as Ethiopia's Health Extension Programs primarily targets to address maternal and child health problems specifically in addressing family planning services at household level. However women living on street, around churches and mosques living by begging cannot be addressed by health extension packages, only those beggars who have rented houses can be addressed by health extension packages, though modern contraceptive use among women beggars is scarce and not well known in the study area. This study aims to assess modern contraceptive utilization and associated factors among women beggars in Bahir Dar town, North Western Ethiopia. A quantitative cross-sectional study was conducted in March 2019 from Bahir Dar town, Northwestern Ethiopia on 238 women beggars using consecutive sampling technique with an interviewer administered structured questionnaire. Data was entered in to Epi-Info version 7 then, exported to SPSS version 23 for cleaning and analysis. Binary logistic regression analysis was used to determine the association between different factors and modern contraceptive service utilization. Those variables which had significant association with modern contraceptive service utilization were entered to multivariable logistic regression analysis. Finally odds ratio with $95 \%$ confidence intervals were used to identify the independent predictors of modern contraceptive utilization by women beggars. One hundred fifteen $(48.9 \%)$ have ever used and seventy three $(31.1 \%)$ with $(95 \% \mathrm{CI}=25.1-37.4 \%)$ were currently using modern contraceptives, $44(60.3 \%)$ use injectable followed by implant $11(15.1 \%)$. Being married (AOR=4.850 \& 95\%CI 2.285-6.971), being educated ( $\mathrm{AOR}=5.771 \& 95 \% \mathrm{CI} 3.173-6.564)$, currently living in a rented house ( $\mathrm{AOR}=2.155 \& 95 \% \mathrm{CI}$ 1.523-3.623), having a history of sexual assault/rape (AOR=3.846 \& 95\%CI 2.133-5.448) and having discussion with a HEW (AOR=3.173 95\%CI 2.154-3.889) were more likely to be modern contraception users than their counter parts. The current contraceptive use among women beggars in Bahir Dar town Northwestern Ethiopia is lower considering the natures of their life styles and living conditions though working by including them in urban health extension program by targeting the identified factors is more helpful.
\end{abstract}

Keywords: Women Beggars, Modern Contraceptive Utilization, Bahir Dar, Northwestern Ethiopia

\section{Introduction}

\subsection{Background}

Family planning refers to the use of various methods of fertility control that will help individual men and women or couples to have the number of children they want when they want them in order to assure the wellbeing of the children and the parents. All individuals and couples have a basic human right to decide freely and responsibly the number, spacing, and timing of their children. [1].

In 2017, world population numbered 7.6 billion. Africa accounts to more than 17 per cent ( 1.3 billion) of the world population of which, Ethiopia, the second populous country in Africa contributes 105 million people. The average total fertility rate (TFR) worldwide ranges from 1.7 children per women in more developed countries to 4.3 in the least developed nations and 4.2 children per women in Ethiopia. This puts Ethiopia among countries with the highest fertility rates in the world. For fertilities to fall to those low levels, 
the increased use of modern contraceptive methods plays a significant role especially in the less developed countries including Ethiopia [2].

Besides its effect on fertility reduction, the use of modern contraceptive methods has a clear effect on the health of women, children, and families. Contraceptive use is also shown to improve child survival through optimal child spacing, lengthening birth intervals, and reducing sibling competition for scarce family and maternal resources. There are at least four causal mechanisms through which family planning can directly reduce maternal deaths: reduce exposure to incidence of pregnancy, reduce vulnerability to abortion risks, postpone pregnancies during prematurity of pelvis development by delaying the first birth, and reduce the hazards of frailty from high parity pregnancies [3].

Globally, contraceptives help to prevent an estimated 2.7 million infant deaths and the loss of 60 million of healthy life in a year. It averts $(32 \%)$ of all maternal deaths and nearly $(10 \%)$ of childhood deaths and has the potential to reduce poverty and hunger especially in developing countries [4].

Federal ministry of health of Ethiopia set goal to reach CPR from $29 \%$ by 2011 to $74.4 \%$ by 2035 , in the projection that the effect of achieving CPR $74.4 \%$ by 2035 will decrease TFR to be 1.5 at the end of 2035 [5]. The HSTP 2015/20162019/2020 also set goals to reduce Total Fertility Rate (TFR) from 4.1 to 3 and Increase Contraceptive Prevalence Rate (CPR) from $42 \%$ to $55 \%$ [6].

In order to achieve this goal the Ministry needs critical strategies to address the whole communities. In the past decade, considerable efforts have been made by the government of Ethiopia and various local and international partners such as: UN, UNICEF, WHO, FAO, WFP and UNFPA, which focuses mainly on family planning services and expand family planning programs and services through building health infrastructure and the introduction of the health extension package (HEP) [7].

Though Health Extension Workers (HEWs) who provide modern contraceptive methods are assigned to the doorstep and household levels in rural as well as urban kebeles [8], however; the utilization of modern contraceptive methods among women beggars is not known. This could be due to the reality that peoples living on street, around churches and mosques living by begging cannot be addressed by HEP only those beggars who have rented houses can be addressed by health extension packages as Ethiopia's HEP primarily targets to address health problems at household level [9].

Begging is a last resort of coping mechanism of poverty, disability and various political, social and environmental crises. It is practiced to obtain alms from others in the form of food money or other goods and materials [9]. Beggars are at high risk for violence, injury or abuse, challenge in accessing health service, discrimination and exploitation. Virtually all beggars attribute their start of begging to one or more types of health problems. People with different abilities make up significant part of beggars, those include, persons who are blind, deaf or have other physical impairment, intellectual impairment and disability related to mental health. The needs of person with different abilities are less likely to be met in developing countries [10].

At present, although the national modern contraceptive use increased substantially from $6 \%$ in 2000 to $35 \%$ in 2016 and from $8 \%$ in 2000 to $47 \%$ in 2016 in Amhara region [3]. However, modern contraceptive utilization of under privileged and specific people is not known. Beggars are among those non privileged section of the community.

\subsection{Statement of the Problem}

Utilization of modern contraceptive methods is important for the reduction of fertility and population growth avoiding unwanted pregnancy and improving maternal and child health. Yet 214 million women of reproductive age in developing regions who want to avoid pregnancy are not using a modern contraceptive method, 155 million who use no method of contraception and 59 million who rely on traditional methods. The proportion of women who have an unmet need for modern contraception is highest in SubSaharan Africa (21\%) and Ethiopia is $(22 \%)$ [3, 11].

From the estimated 206 million pregnancies in 2017 in developing regions, $43 \%$ are unintended pregnancy. Each year, 1.9 million (38\%) Ethiopian women have an unintended pregnancy (13\%) end in abortion [7]. In 2017, an estimated 308,000 women in developing countries died from pregnancy-related causes, and 2.7 million babies died in the first month of life [11].

As Ethiopia HEP with their partner plan to tackle maternal and child health problems and to improve modern contraceptive to each household level, ignoring these under privileged segment of the population challenges its achievement. Women beggars are not suffering from economic burden alone, but also reproductive health problems including modern contraceptive services are among many of the problems those women face [10]. Virtually all beggars attribute their start of begging to one or more types of health problems [9].

Beggars with disabilities in particular are often viewed as sexual inactive, incapable of engaging in a sexual relationship, unable to bear and raise children, which severely limit the information and type of reproductive health services made available. However, persons with disability are as likely to be sexually active as person without disability and need both information and services related to modern contraceptive methods. The challenges to use modern contraceptives faced by persons with disabilities are not only because of the disability, but also reflect lack of social attention, legal protection and support [12].

Over all these Challenging Ethiopia who pledged during the 2012 London summit to uphold the rights of all Ethiopians to access voluntary family planning with special attention to serving isolated communities [13]. Therefore the current study was conducted with the intent to assess modern contraceptive method utilization and its associated factors among reproductive aged women beggars of Bahir Dar town Northwestern Ethiopia. This study was expected to fill the existing information gap about the barriers that affect 
utilization of modern contraceptives of women beggars and will be an input for policy makers and partners to design appropriate interventions for such vulnerable population.

\subsection{Significance of the Study}

Women beggars are economically socially and nutritionally disadvantaged, it is common to see them holding two to three babies by their side's, evidence on the predictors of modern contraceptive method utilization and factors affecting its utilization were scarce and not well known in the context of women beggars in the study area.

So assessing the current utilization status of modern contraceptives and identifying socio demographic/socio economic issues and other associated factors that are barriers to use of contraceptive methods by women beggars is important to determine evidence based strategies to enhance the modern contraceptive service in these under privileged population which in turn helps to improve the health of mothers and children of Bahir Dar town, Amhara region and the whole country.

Though several studies were conducted on modern contraceptive utilization, but studies are limited for these specific population groups. Hence, this study aimed to assess modern contraceptive utilization and associative factors of women beggars, so this research would help to fill the gap in existing literature.

The research would benefit government, NGO service providers and policy makers in developing strategies to further improve service delivery to women beggars. The study finding may also play a role towards improving effective use of contraceptives and family planning services, and thereby contribute towards achieving the HSTP, SDG and the projection of 2035 contraceptive prevalence rate and by decreasing maternal and child mortality.

\section{Objective}

\subsection{General Objective}

To assess modern contraceptive utilization and associated factors among women beggars in Bahir Dar town, North West Ethiopia 2019

\subsection{Specific Objectives}

1. To determine the proportion of women beggars using modern contraceptive in Bahir Dar town, north West Ethiopia 2019

2. To identify factors associated with modern contraceptive use among women beggars in Bahir Dar town, North West Ethiopia 2019

\section{Methods}

\subsection{Study Design, Area and Period}

Quantitative Cross-sectional study was used.

The study was conducted in March 2019 in Bahir Dar
North West Ethiopia. Based on the 2007 national census conducted by CSA Bahir Dar special zone has a total population of 221,991 , of whom 108,456 are men and 113,535 women [32]. A total of 569 women beggars live in Bahir Dar as obtained from Federal Ministry of Labour and Social Affairs of Bahir Dar [34].

\subsection{Source Population and Study Population}

The source population for this study was women beggars living in Bahir Dar town

The study population was women beggars living in Bahir Dar town who are at the study area at the study period.

\subsection{Inclusion and Exclusion Criteria}

\subsubsection{Inclusion Criteria}

Women beggars of reproductive age group (age between 15 and 49) who were found in the study area at a time of data collection was included.

\subsubsection{Exclusion Criteria}

Women of reproductive age group, those who can't hear or speak were excluded.

\subsection{Study Variables}

\subsubsection{Dependent Variable}

Modern contraceptive use

\subsubsection{Independent Variables}

Age

Marital status

Educational status

Residence before engaged to begging

Current living

Daily income

Perceived social support

History of sexual Assault/rape

Unwanted pregnancy

Induced Abortion

Desire of children in the future

Knowledge on modern contraceptive use

Attitude towards modern contraceptive use

Source of Information about modern contraception

Discussion with HEW

Disability of women beggars

Presence of chronic illness in women beggars

\subsection{Operational Definition}

Modern contraceptive ever user: A woman who has ever using any of the MCs methods.

Modern contraceptive current user: A woman using any one of the MCs methods at the time of the survey.

Good knowledge of modern contraceptive: after scoring total five knowledge questions those respondents who respond above or equal to average mean value were considered as having good knowledge for contraceptive methods. 
Poor knowledge of modern contraceptive: after scoring total five knowledge questions those respondents who respond below average mean value were considered as having poor knowledge for contraceptive methods.

Favorable attitude: Those respondents who responded above the mean value for cumulative ten attitudinal questions.

Unfavorable attitude: Those respondents who responded the mean and below mean value for cumulative ten attitudinal questions.

Beggars: are people living by begging a gift of money on the main concentration areas.

Disability: by using WHO disability assessment criteria

Chronic illness condition: is a disease condition that is persistent or otherwise long-lasting in its effects or a disease that comes with time. The term chronic is often applied when the women had any one of the common known comorbid illness such as DM, HIV, Hypertension, cardiac illness, and TB.

Perceived social support: By using Oslo scale I summarizing the raw scores, the sum ranging from 3-14. A score of 3-8 is "poor support", 9-11 is "moderate support" and $12-14$ is "strong support".

\subsection{Sample Size Determination}

As the knowledge of the investigator there was no study accessed on modern contraceptive utilization and its associated factors of women beggars. So by considering their similar living condition and life status of street females with women beggars, I was used to calculate sample size using a proportion of current modern contraceptive use by a study done on awareness and utilization of modern contraceptives among street women in North-West Ethiopia, which was $34.3 \%$ [26]. Then actual sample size was calculated using a single population proportion formula of

$$
\begin{gathered}
\mathrm{n}=\frac{(z \alpha / 2) 2 \mathrm{pq}}{d 2} \\
\mathrm{n}=\frac{(1.96) 2(0.343)(0.657)}{(0.05) 2}=346.28
\end{gathered}
$$

Where $\mathrm{n}=$ the required sample size

$\mathrm{p}=$ the proportion of contraceptive prevalence among women beggars (street females in Northwest Ethiopia 34.3\%) (26).

$\mathrm{Z} \alpha / 2=$ the critical value at $95 \%$ confidence level of certainty (1.96).

$\mathrm{d}=$ the margin of error between the sample and the population $=5 \%$.

Thus, the study should include 347 study subjects, then the total source population in the town was known which were a total of 569 female beggars as obtained from Ministry of Labour and Social Affairs of Bahir Dar (34), the required minimum sample were obtain from the above estimate by making some adjustments for finite population.

$\mathrm{n}=347 /(1+(347 / 569)=216$

Therefore, the study was included 216 study subjects plus
$10 \%$ non- response. Then the final sample size was 238 women beggars in Bahir Dar town.

\subsection{Sampling Procedures}

A total 238 women beggar selected from sample of women beggars. Based on the information obtained from the Ministry of Labour and Social Affairs of Bahir Dar, there are main concentration areas of women beggars 13 churches, 2 mosque and 3 main road sides were identified. Therefore data collection was done on women beggars of child bearing age found in the morning of Sunday around churches, main road sides and on Friday around mosques. Each women beggar was taken by consecutive sampling technique from each church, mosque and road sides. Data collection was ended within a day in a town to prevent redundancy. Prior to data collection no information was obtained on the exact number of women beggars in each church, mosque and main road sides. Hence, assuming an equal distribution of beggars in each church, mosque and road side's fifteen data collectors was distributed to each main concentration areas. In case the required sample was not obtained in the selected main concentration areas, data collector was gone to the nearby churches, mosques or main road sides to get the required samples.

\subsection{Data Collection and Analysis Procedures}

\subsubsection{Data Collection Instrument}

Structured interviewer administrated questionnaire was used for data collection. The instruments was prepared by referring relevant literature and by adopting from similar instruments used earlier.

The questionnaire was first translated to Amharic and then back to English for checking consistency.

\subsubsection{Data Collectors}

Seventeen diploma holding nurses were trained for data collector (15) and supervisor (2). They were trained on the objective of the study, content and flow of the questionnaires. Emphasis was given on how to approach the study participants, keeping their privacy and respecting their dignity. The training was given for one day.

Data collection was done in the mornings of Sunday and Friday when begging was not started at churches mosques main road sides and bus stations where beggars were usually observed. We painted each participant on left index finger after interview. When they were busy with their business we meet them to come after a time by giving taxi incentives. Data collectors were told to check each study participant's left hand index finger to void double interview. All the trained data collectors were participated in the data collection process.

\subsubsection{Data Quality Assurance}

For data quality control purpose, the data collectors and supervisors were trained before the data collection. Supervision was done during the data collection period and the questionnaires were pretested. The pre-test was done on 
(5\% of the sample size) women beggars in March 92018 from Merawi town.

The questionnaire was first translated to Amharic and then back to English for checking consistency. The collected data were reviewed and checked for completeness before data entry and incomplete data was discarded.

\subsubsection{Data Analysis}

The data were entered into EPI Info version 7 and then exported to SPSS version 23 statistical program. Descriptive statistics of percentages mean and frequency distribution using tables were carried. In addition bivariable logistic regression analysis was used to determine the association between different factors and MCs service utilization. Those variables which had significant association with MCs service utilization were entered to multivariable logistic regression analysis. Finally odds ratio with $95 \%$ confidence intervals and $p$ value 0.005 was used to identify the independent predictors of modern contraceptive utilization by women beggars.

\section{Result}

A total of 238 sexually active women Beggars participated in the study with $100 \%$ response rate; three was excluded for incomplete answer.

\subsection{Socio Demographic Characteristics of Respondents}

The mean and median age of participants was $29.28 \&$ $28 \pm 7.75$ SD years respectively. $95(40.4 \%)$ were aged (2029). Nearly two third $180(76.6 \%)$ were rural residents before they got engaged in Begging life. Eighty nine (37.9\%) were married, 221 (94.0\%) were Orthodox Christians, Amhara ethnics $181(77.0 \%)$ and don't read and write 115 (49.0\%). Seventy three $(31.1 \%)$ women beggars had chronic illness of these 32 (43.8\%) had HIV followed by $13(17.8 \%)$ diabetes mellitus and Cardiac illness. Fifty six $(23.8 \%)$ of participants had disability of which $42(75 \%)$ had moderate disability followed by $13(23.2 \%)$ severe disability among these 26 (46.4\%) face blindness followed by $24(42.9 \%)$ physical handicaps [table 1].

Table 1. Socio demographic characteristics of women beggars in Bahir Dar town northwest Ethiopia March 2019

\begin{tabular}{lll}
\hline Variables & Frequency & Percent $(\mathbf{\%})$ \\
\hline Age of respondents $(\mathrm{n}=235)$ & 37 & 15.7 \\
$<20$ & 95 & 40.4 \\
$20-29$ & 75 & 31.9 \\
$30-39$ & 28 & 11.9 \\
$40-49$ & 180 & 76.6 \\
Residence before engaging to begging $(\mathrm{n}=235)$ & 23.4 \\
Rural & 55 & \\
Urban & & \\
Religion (n=235) & 221 & 94.0 \\
Orthodox Christian & 12 & 5.1 \\
Muslim & 2 & 0.9 \\
Other* & & \\
Ethnicity (n=235) & 181 & 77.0 \\
Amhara & & \\
\hline
\end{tabular}

\begin{tabular}{|c|c|c|c|}
\hline \multicolumn{2}{|l|}{ Variables } & Frequency & Percent (\%) \\
\hline \multicolumn{2}{|l|}{ Agew } & 46 & 19.6 \\
\hline \multicolumn{2}{|l|}{ Oromo } & 6 & 2.6 \\
\hline \multicolumn{2}{|l|}{ Others** } & 2 & 0.9 \\
\hline \multicolumn{4}{|l|}{ Marital Status $(n=235)$} \\
\hline \multicolumn{2}{|l|}{ Single } & 56 & 23.8 \\
\hline \multicolumn{2}{|l|}{ Married } & 89 & 37.9 \\
\hline \multicolumn{2}{|l|}{ Divorced } & 57 & 24.3 \\
\hline \multicolumn{2}{|l|}{ Widowed } & 33 & 14.0 \\
\hline \multicolumn{4}{|c|}{ Educational Status (n=235) } \\
\hline \multicolumn{2}{|l|}{ Don't read and write } & 115 & 49.0 \\
\hline \multicolumn{2}{|l|}{ Only read and write } & 44 & 18.7 \\
\hline \multicolumn{2}{|l|}{ Primary (1-8) } & 49 & 20.8 \\
\hline \multicolumn{2}{|l|}{ Secondary $(9-12)$} & 27 & 11.5 \\
\hline \multicolumn{4}{|l|}{ Disability (n=235) } \\
\hline \multirow{4}{*}{ Yes $(n=56)$} & & 56 & 23.8 \\
\hline & Mild & 1 & 1.78 \\
\hline & Moderate & 42 & 75 \\
\hline & Severe & 13 & 23.2 \\
\hline \multicolumn{2}{|l|}{ No } & 179 & 76.2 \\
\hline \multicolumn{4}{|c|}{ Type of Disability or Impairment $(\mathrm{n}=56)$} \\
\hline \multicolumn{2}{|c|}{ Blindness } & 26 & 46.4 \\
\hline \multicolumn{2}{|l|}{ Difficulty of Hearing } & 1 & 1.8 \\
\hline \multicolumn{2}{|l|}{ Mental Illness } & 5 & 8.9 \\
\hline \multicolumn{2}{|l|}{ Physical Handicaps } & 24 & 42.9 \\
\hline \multicolumn{4}{|l|}{ Chronic Illness ( $\mathrm{n}=235$ ) } \\
\hline \multicolumn{2}{|l|}{ Yes } & 73 & 31.1 \\
\hline \multicolumn{2}{|l|}{ No } & 162 & 68.9 \\
\hline \multicolumn{4}{|c|}{ Type of Chronic Illness $(n=73)$} \\
\hline \multicolumn{2}{|l|}{ Cardiac Illness } & 13 & 17.8 \\
\hline \multicolumn{2}{|l|}{ DM } & 13 & 17.8 \\
\hline \multicolumn{2}{|l|}{ ТВ } & 10 & 13.7 \\
\hline \multicolumn{2}{|l|}{ HIV } & 32 & 43.8 \\
\hline Others $* * *$ & & 5 & 6.8 \\
\hline
\end{tabular}

$\mathrm{NB}=$ other $*=$ Protestant, Catholic Other $* *=$ Tigray, Gumz other $* * *=$ cancer, chronic kidney disease, Hypertension.

\subsection{Socio Economic Characteristics of Respondents}

Among the study participants majority were not employed and were living only by begging 109 (46.4\%), had income 30 or less per day $144(61.3 \%)$ and live in rented house 100 $(42.6 \%)$ followed by Mass living room 59 (25.1\%). One hundred thirty eight $(58.7 \%)$ had poor perceived social support followed by $49(20.9 \%)$ moderate perceived social support. Among the respondents the main reason to be a beggar was unemployment $155(66 \%)$ followed by chronic illness $32(13.6 \%)$ and disability $(10.2 \%)$ [table 2 ].

Table 2. Socio Economic characteristics of women beggars in Bahir Dar town northwest Ethiopia March 2019.

\begin{tabular}{lll}
\hline Variables & Frequency & Percent \\
\hline Jobs in Addition to Begging $(\mathrm{n}=235)$ & & \\
Only Begging & 109 & 46.4 \\
Daily Laborer & 52 & 22.7 \\
House Wife & 37 & 15.7 \\
Cent exchange & 27 & 11.5 \\
Student & 9 & 3.8 \\
Other* & 1 & 0.4 \\
Daily income in Ethiopian Birr $(\mathrm{n}=235)$ & \\
$<=30$ & 144 & 61.3 \\
$31-40$ & 41 & 17.4 \\
$41-50$ & 42 & 17.9 \\
$>=51$ & 8 & 3.4 \\
Reason to be a Beggar $(\mathrm{n}=235)$ & & \\
\hline
\end{tabular}




\begin{tabular}{lll}
\hline Variables & Frequency & Percent \\
\hline Unemployment & 155 & 66.0 \\
Chronic Illness & 32 & 13.6 \\
Disability or Impairment & 24 & 10.2 \\
Displacement & 17 & 7.2 \\
Death of Supporter/Family member & 7 & 3.0 \\
Current Living (n=235) & & \\
Rented House & 100 & 42.6 \\
Mass Living Room & 59 & 25.1 \\
Church/Mosque area & 36 & 15.3 \\
On the Street & 26 & 11.1 \\
Near to somebody & 14 & 6.0 \\
Perceived Social Support (n=235) & & \\
Poor support & 138 & 58.7 \\
Moderate Support & 49 & 20.9 \\
Good Support & 48 & 20.4 \\
\hline
\end{tabular}

$\mathrm{NB}=$ other $^{*}=$ street dwellers.

\subsection{Reproductive Characteristics of Respondents}

From the study participants, $92(39.1 \%)$ had a history of sexual assault or rape with a median age of first raped 17 year and $172(73.2 \%)$ had pregnancy history with a median age 18 years of first pregnancy. Forty $(65.6 \%)$ respondents raped before eighteen years and $70(54.3 \%)$ had their first pregnancy before eighteen years of age.

Ninety four $(54.7 \%)$ participants experienced unwanted pregnancy of these $39(41.5 \%)$ first pregnancy was unwanted followed by $22(23.4 \%)$ last pregnancy. When asked about their cause of unwanted pregnancy $45(47.9 \%)$ were due to lack of modern contraceptive services followed by 35 $(37.2 \%)$ sexual abuse/rape and $8(8.5 \%)$ husband/partner opposition.

From the study participants $40(23.3 \%)$ had a history of Induced abortion of which 14 (35\%) of them aborted by selftaking different drugs followed by 12 (30\%) cultural abortionist. Of those 30 (12.8\%) encountered ones followed by $5(2.1 \%)$ three times. Majority of the respondents 141 $(82.0 \%)$ had children and $95(40.4 \%)$ want children in the future [table 3].

Table 3. Reproductive characteristics of women beggars in Bahir Dar town northwest Ethiopia March 2019.

\begin{tabular}{lll}
\hline Variables & Frequency & Percent (\%) \\
\hline Sexual assault/Rape $(\mathrm{n}=235)$ & 92 & 39.1 \\
Yes & 143 & 60.9 \\
No & & \\
Pregnancy History $(\mathrm{n}=235)$ & 172 & 73.2 \\
Yes & 63 & 26.8 \\
No & & \\
Unwanted pregnancy $(\mathrm{n}=172)$ & 94 & 54.7 \\
Yes & 78 & 45.3 \\
No & & \\
Which pregnancy was unwanted $(\mathrm{n}=94)$ & 39 & 41.5 \\
First & 12 & 12.8 \\
Second and other & 22 & 23.4 \\
Last & 21 & 22.3 \\
All & & \\
Reason for Unwanted Pregnancy $(\mathrm{n}=94)$ & 45 & 47.9 \\
Lack of Modern contraceptive services & 45 & 8.5 \\
Partner opposition & 8 & 37.2 \\
Sexual Assault/rape & 35 & 6.4 \\
Other* & 6 & \\
\hline
\end{tabular}

\begin{tabular}{lll}
\hline Variables & Frequency & Percent (\%) \\
\hline History of Induced abortion (n=172) & & \\
Yes & 40 & 23.3 \\
No & 132 & 76.7 \\
Place she aborted (n=40) & & \\
Public health institution & 9 & 22.5 \\
untrained abortionist & 12 & 30.0 \\
Self-taking different methods & 14 & 35.0 \\
Others** & 5 & 12.5 \\
Have children (n=172) & & \\
Yes & 141 & 82.0 \\
No & 31 & 18.0 \\
Number of children's (n=141) & & \\
$<3$ & 81 & 57.4 \\
$>=3$ & 60 & 42.6 \\
Want children in the future (n=235) & & \\
Yes & 95 & 40.4 \\
No & 140 & 59.6 \\
Why you want children in this situation $(\mathrm{n}=95)$ & \\
Children's are a gift from God & 33 & 34.7 \\
When we Hold children alms givers & 18 & 18.9 \\
increase & & \\
Need help in the future & 27 & 28.4 \\
Other*** & 17 & 17.9 \\
\hline
\end{tabular}

$\mathrm{NB}=$ others ${ }^{*}=$ not perceiving the occurrence of pregnancy, lack of knowledge other**=private clinic other***=to replace my self.

\subsection{Knowledge and Attitude Towards Modern Contraceptive Use}

Most 207 (88.1\%) of the study participants were ever heard about modern contraceptive methods of them, 144 $(61.3 \%)$ heard from friends or neighbor's followed by 96 $(40.9 \%)$ from Health professionals. The most known modern contraception methods was injectable $148(63.0 \%)$ followed by oral contraceptive pills $90(38.3 \%)$ and condom 44 (18.7\%). Birth spacing 103 (43.8\%) was the most commonly mentioned advantages of modern contraceptives by women beggars. Overall, $207(88.1 \%)$ and $156(66.4 \%)$ of women beggars had good knowledge and favorable attitude towards modern contraceptive respectively. In this study 77 (32.8\%) of the respondent had discussion with a HEW [table 4].

Table 4. Knowledge and attitude of women beggars in Bahir Dar town northwest Ethiopia March 2019.

\begin{tabular}{lll}
\hline Variables & Frequency & Percent (\%) \\
\hline Ever heard about MCs (n=235) & 207 & 88.1 \\
Yes & 28 & 11.9 \\
No & & \\
Source of information about MCs (n=207) & 144 & 61.3 \\
Friends/Neighbors & 96 & 40.9 \\
Health Professionals & 62 & 26.4 \\
Mass media & 6 & 2.6 \\
School & 1 & 0.4 \\
Others* & 90 & 38.3 \\
Type of MCs methods Known by a respondent (n=207) & \\
Oral contraceptive pills & 44 & 18.7 \\
Condom & 148 & 63.0 \\
Injectable & 26 & 11.1 \\
Implant & 33 & 14.0 \\
IUCD & 1 & 0.4 \\
Others** & & \\
Advantages of MCs mentioned (n=207) & 103 & 43.8 \\
Birth Spacing &
\end{tabular}




\begin{tabular}{lll}
\hline Variables & Frequency & Percent (\%) \\
\hline Prevent Unwanted pregnancy & 68 & 28.9 \\
Prevent STI & 52 & 22.1 \\
Limit family size & 69 & 29.4 \\
Health Education from HEW (n=235) & & \\
Yes & 77 & 32.8 \\
No & 158 & 67.2 \\
Knowledge towards MCs use (n=235) & & \\
Good Knowledge & 207 & 88.1 \\
Poor Knowledge & 28 & 11.9 \\
Attitude towards MCs use $(\mathrm{n}=235)$ & & \\
Favorable & 121 & 51.5 \\
Unfavorable & 114 & 48.5 \\
\hline
\end{tabular}

$\mathrm{NB}=$ other*$^{*}=$ husband/partner other**=lactation amenorrhea method.

\subsection{Utilization of Modern Contraceptives}

Nearly half of the study participants 115 (48.9\%) have ever used any Modern contraception method of which 70 $(60.9 \%)$ used inject-able followed by oral contraceptive pills $14(12.2 \%)$. From $120(51.1 \%)$ who never used modern contraceptives lack of modern contraceptive service 42 (35\%), want to have children $36(30 \%)$ and Husband/partner opposition $19(15.8 \%)$ were the main reasons for not using modern contraceptives. From those Ever users 48 (41.7\%) were stopped due to fear of side effect $16(33.3 \%)$ partner opposition 16 (33.3\%) and misconception/rumor 7 (14.6\%). This revealed that $73(31.1 \%)$ with $(95 \% \mathrm{CI}=25.1-37.4 \%)$ of women beggars were currently using modern contraceptives and from those current non users $83(51.2 \%)$ want to use modern contraception's in the future [table 5].

Table 5. Modern contraceptive utilization of women beggars in Bahir Dar town northwest Ethiopia March 2019.

\begin{tabular}{|c|c|c|}
\hline Variables & Frequency & Percent (\%) \\
\hline \multicolumn{3}{|l|}{ Ever use of MCs $(n=235)$} \\
\hline Yes & 115 & 48.9 \\
\hline No & 120 & 51.1 \\
\hline \multicolumn{3}{|c|}{ Type of Methods Ever used ( $\mathrm{n}=115)$} \\
\hline Oral Contraceptive Pills & 14 & 12.2 \\
\hline Condom & 5 & 4.3 \\
\hline Injectable & 70 & 60.9 \\
\hline Implant & 13 & 11.3 \\
\hline IUCD & 13 & 11.3 \\
\hline \multicolumn{3}{|c|}{ If no why you are not using MCs $(n=120)$} \\
\hline Lack of MCs services & 42 & 35.0 \\
\hline Want to have children & 36 & 30.0 \\
\hline Fear of side effect & 14 & 11.7 \\
\hline Husband/partner opposition & 19 & 15.8 \\
\hline Others* & 9 & 7.5 \\
\hline \multicolumn{3}{|l|}{ Accessibility of MCs (n=235) } \\
\hline Yes & 162 & 68.9 \\
\hline No & 73 & 31.1 \\
\hline \multicolumn{3}{|c|}{ Default after ever use of MCs ( $n=115)$} \\
\hline Yes & 48 & 41.7 \\
\hline No & 67 & 58.3 \\
\hline \multicolumn{3}{|c|}{ Current MCs service utilization $(\mathrm{n}=235)$} \\
\hline Yes & 73 & 31.1 \\
\hline No & 162 & 68.9 \\
\hline \multicolumn{3}{|c|}{ Type of methods currently used ( $\mathrm{n}=73$ ) } \\
\hline Oral Contraceptive pills & 9 & 12.3 \\
\hline Injectable & 44 & 60.3 \\
\hline Implant & 11 & 15.1 \\
\hline IUCD & 9 & 12.3 \\
\hline
\end{tabular}

\begin{tabular}{lll}
\hline Variables & Frequency & Percent (\%) \\
\hline Need to use MCs in the future $(\mathrm{n}=162)$ & & \\
Yes & 83 & 51.2 \\
No & 79 & 48.8 \\
\hline
\end{tabular}

$\mathrm{NB}=$ other*=perceiving not sexually active, have no husband/partner. Modern contraceptive utilization of women beggars.

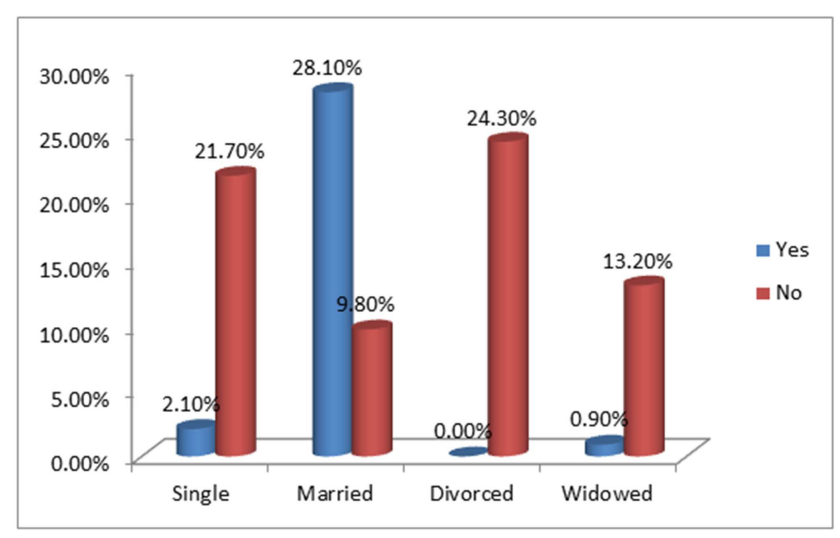

Marital status of women beggars.

Figure 1. Modern contraceptive utilization of women beggars by marital status in Bahir Dar town northwest Ethiopia March 2019.

\subsection{Factors Associated with Modern Contraceptive Service Utilization}

Binary logistic regression was done to identify significant factors associated with modern contraceptive service utilization then the significant variables were taken to multivariable logistic regression.

Binary logistic regression analysis showed age, marital status, educational status, residence before engaging to begging, daily income, current living, having additional jobs, history of sexual assault/rape, future desire of children, perceived accessibility of MCs service, discussion with a HEW, disability and presence of chronic illness were significantly associated with modern contraceptive service utilization of women beggars.

Then the multivariable logistic regression analysis showed that there was statistically significant association between modern contraceptive service utilization and marital status, educational status, current living of women beggars, having a history of sexual assault/rape and having discussion with a HEW.

Among Women beggars married women were 4.8 times $(\mathrm{AOR}=4.850 \& 95 \% \mathrm{CI}$ 2.285-6.971) more likely to be current modern contraceptive users as compared to currently unmarried women (single, divorced or widowed).

Educated women were 5 times $(\mathrm{AOR}=5.771 \&$ \& $95 \% \mathrm{CI}$ 3.173-6.564) more likely to be current modern contraceptive users as compared to non-educated (not read and write and only read and write).

Among women beggars those who are currently living in a rented house were 2 times $(\mathrm{AOR}=2.155 \& 95 \% \mathrm{CI} 1.523$ 3.623) more likely to utilize modern contraceptives as compared to those who are living in a mass living room around church and mosque and on the street. 
In this study those women beggars who had discussion with a HEW were 3 times ( $\mathrm{AOR}=3.17395 \% \mathrm{CI} 2.154-3.889)$ more likely to utilize modern contraception's.

Among women beggars those who had a history of sexual assault/rape were 3 times $(\mathrm{AOR}=3.846 \&$ \& 95\%CI 2.1335.448) more likely to use modern contraceptive services as compared to those who had no a history of sexual assault/rape [table 6].

Table 6. Logistic regression of associated factors with modern contraceptive use in Bahir Dar town northwest Ethiopia March 2019.

\begin{tabular}{|c|c|c|c|c|c|}
\hline \multirow{2}{*}{ Explanatory variables } & \multicolumn{2}{|c|}{ MCs utilization } & \multirow{2}{*}{$\operatorname{COR}(95 \% \mathrm{CI})$} & \multirow{2}{*}{$\operatorname{AOR}(95 \% C I)$} & \multirow{2}{*}{ P-value } \\
\hline & Yes & No & & & \\
\hline \multicolumn{6}{|l|}{ Marital Status } \\
\hline Married & 62 & 27 & 1 & 1 & \multirow{2}{*}{$0.001 *$} \\
\hline Unmarried & 11 & 135 & $31.063(15.640-74.186)$ & $4.850(2.285-6.971)$ & \\
\hline \multicolumn{6}{|l|}{ Educational Status } \\
\hline Educated & 63 & 13 & 1 & 1 & \multirow{2}{*}{$0.000 *$} \\
\hline Non-Educated & 10 & 149 & $72.208(30.087-173.294)$ & $5.771(3.173-6.564)$ & \\
\hline \multicolumn{6}{|l|}{ Current living } \\
\hline Live on rented house & 55 & 45 & 1 & 1 & \multirow{2}{*}{0.013} \\
\hline Mass living and others & 18 & 117 & $7.944(4.216-14.970)$ & $2.155(1.523-3.623)$ & \\
\hline \multicolumn{6}{|c|}{ Discussion with a HEW about MCs } \\
\hline Yes & 62 & 15 & 1 & 1 & \multirow{2}{*}{$0.001 *$} \\
\hline No & 11 & 147 & $55.236(24.021-127.019)$ & $3.173(2.154-3.889)$ & \\
\hline \multicolumn{6}{|l|}{ Rape } \\
\hline Yes & 57 & 35 & 1 & 1 & \multirow{2}{*}{$0.003 *$} \\
\hline No & 16 & 127 & $12.927(6.622-25.235)$ & $3.846(2.133-5.448)$ & \\
\hline \multicolumn{6}{|l|}{ Age category } \\
\hline $15-24$ & 19 & 45 & 1 & & \\
\hline $25-34$ & 47 & 61 & $1.825(0.946-3.522)$ & & \\
\hline $35-49$ & 7 & 56 & $0.296(0.114-0.766)$ & & \\
\hline \multicolumn{6}{|l|}{ Additional Job } \\
\hline Had additional job & 49 & 77 & 1 & & \\
\hline Only begging & 24 & 85 & $2.254(1.265-4.015)$ & & \\
\hline \multicolumn{6}{|c|}{ Daily income in Ethiopian Birr } \\
\hline$>=30$ & 61 & 41 & 1 & & \\
\hline$<30$ & 12 & 121 & $15.002(7.353-30.609)$ & & \\
\hline \multicolumn{6}{|c|}{ Residence before engaging to begging } \\
\hline Urban & 39 & 16 & 1 & & \\
\hline Rural & 34 & 146 & $10.467(5.243-20.895)$ & & \\
\hline \multicolumn{6}{|c|}{ Perceived accessibility of MCs } \\
\hline Yes & 58 & 104 & 1 & & \\
\hline No & 15 & 58 & 2.1561 .1234 .140 & & \\
\hline \multicolumn{6}{|l|}{ Disability } \\
\hline Yes & 28 & 28 & 1 & & \\
\hline No & 45 & 134 & $2.978(1.597-5.553)$ & & \\
\hline \multicolumn{6}{|l|}{ Want children in the future } \\
\hline Yes & 12 & 61 & 1 & & \\
\hline No & 83 & 79 & $0.187(0.094-0.374)$ & & \\
\hline
\end{tabular}

\section{Discussion}

This study was identified the prevalence of current modern contraceptive utilization of women beggars and its associated factors on a section of the population that is largely ignored; working in this group of the population is of paramount importance. This study reveals that $115(48.9 \%)$ of women beggars have ever used and $73(31.1 \%)$ with $(95 \% \mathrm{CI}=25.1$ $37.4 \%$ ) were currently using modern contraception's. this study was below the finding of a study conducted in South LGA of Plateau state Nigeria among female street traders and Arba Minch Town $51.9 \%$ and $63.4 \%$ respectively [18, 23]. This reveals that modern contraceptive utilization by women beggars is lower due to variation between in the life styles and awareness of women beggars and street traders, lack of accessibility of service and lack of discussion with HEWs.
This result was consistent with a study done in Tanzania, Bangladesh Female Street dwellers, in Ghana, rural Dembia District, north western Ethiopia on street women and in Addis Ababa among street girls which is $(32 \%, 34.5 \%, 27 \%$, $31.7 \%, 34.3 \%$, and $37 \%$ ) respectively $[17,19,20,21,22,26]$. the possible reason might be that somehow the similarity of the life status of women beggars and street women and the time gap of the study. However this result is higher than a study conducted in Bale eco-region, Bale Zone, South East Ethiopia, which is (20.8\%) [25]. The possible reason for the variation might be due to the difference in the residence of study subjects which is women beggars are studied from two major towns which might have better access to modern contraceptives than rural ones.

Seventy $(60.9 \%)$ of beggar women used inject-able followed by oral contraceptive pills $14(12.2 \%)$ and $5(4.3 \%)$ condoms. This result were consistent with a study done in 
rural Dembia District of north western Ethiopia, north western Ethiopia on street women and in Addis Ababa among street girls [22-26]. The possible reason for this can be that short acting modern contraceptive methods were easily accessible in Private pharmacy and private clinics but some long acting methods were accessible only in public health centers and utilizing short acting methods like injectable and pills is universal in the region and all parts of Ethiopia.

Most $207(88.1 \%) \quad(95 \% \mathrm{CI}=83.4-92.4 \%)$ of the study participants were ever heard about modern contraceptive methods. The most known modern contraception methods was injectable $148(63.0 \%)$ followed by oral contraceptive pills $90(38.3 \%)$ and condom $44(18.7 \%)$. This result is also below the Studies in Bale eco-region, South East Ethiopia which is $(95.8 \%)$ and the national and regional results of EDHS 2016 which is $98.9 \%$ and $99.9 \%$ respectively $[3,25]$. The possible reason for the variation is that knowledge about modern contraceptive methods is universal in Ethiopia due to the expansion of health extension packages which is addressed at household levels and there are various governmental and non-governmental organizations working on various angles of maternal health issues including modern contraception, but beggar women were not addressed because of their current living and their mobility during the time of HEWs do. However this result is in line with a study done in north western Ethiopia on street women and in Addis Ababa among street girls, in Ghana street hawker [20, 25, 26]; the possible reason for this might be that similarity of life styles of women beggars and street girls.

Concerning the factors influencing modern contraceptive use, marital status, education, currently living in a rented house, discussion with a health extension worker and history of sexual assault/rape have statistically significant association with modern contraceptive use.

Marital status was one of the factors positively associated with utilization of modern contraceptives. In this study married women were more likely to be current modern contraceptive users as compared to currently unmarried women (single, divorced or widowed). this result is consistent with a study conducted in urban slum areas of India, Nigeria, southern Ethiopia and Dembia district of north western Ethiopia [18, 21, 22, 27]. The result agrees with the fact that marital status is a universal predictor of contraceptive utilization. As compared to the unmarried once married women had better life styles than the unmarried due to economic support and living conditions and they are more likely to live in a rented house though they are supported by health extension workers.

Educational status was one of the important factors to practice modern contraceptive methods. Those women beggars being educated were highly likely to be current modern contraceptive users as compared to non-educated (not read and write and only read and write). these is consistent with, a study conducted in Dhaka Metropolitan Bangladesh of female street dwellers, Mozambique, Wolayta southern Ethiopia North western Ethiopia and Addis Ababa
$[19,22,29,27]$. This reveals that when educational status increase awareness and positive attitude women would increase so utilization would be also improved.

Those women beggars who are currently living in a rented houses were more likely to use modern contraception this should be due to the reality that those health extension workers address services at house hold levels but those women beggars living around churches and mosque, on the street and in a mass living room should not be addressed by a health extension worker.

Having discussion with health extension workers is one of the factors positively associated with modern contraceptive practice. In this study those women beggars who had discussion with a Health Extension Workers were highly likely to utilize modern contraception. This result is supported by a study conducted in Bale eco-region, Bale Zone, South East Ethiopia [25]. This reveals that those women beggars who had discussion with a HEW about modern contraceptive utilization would have good awareness and information and they are utilizing highly. Discussion may also clarify misconceptions and concerns related to modern contraceptive methods and could be encouraged and supported by the HEW to choose the method that best matches to their need. Therefore emphasis should be made to the importance of HEW's scheduled group discussion sessions for women beggars in a fixed place within the main concentration areas those women beggars live or through weekly meeting to expand the possibility of supporting women beggars who are vulnerable and neglected.

In this study having a history of sexual assault/rape were more likely to use modern contraceptive services as compared to those who had no a history of sexual assault/rape. This finding is in line with a study done in street children's in a selected towns of Ethiopia, North West Ethiopia among street women's and among sexually violence Female in Colombia [10, 27, 33].

The possible reason would be women those who had a history of sexual assault or rape may face a risk and they find a means like emergency contraceptive pills due to fear of unintended pregnancy and to prevent further problems and they are asking either a health professional or other person they perceive they are helping them after that they have a chance to discuss about modern contraception, then they have awareness and their utilization of modern contraception will increase.

\section{Strength and Limitations of the Study}

\subsection{Strength}

This study has focused on marginalized and neglected group of people who are highly vulnerable to sexual and reproductive health problems including lack of modern contraceptives where adequate information and studies are lacking. This might certainly fill some of the knowledge gaps and serve as baseline information for future studies. As conducted and collected primary data of community-based 
study bias is somehow minimized.

\subsection{Limitations}

Determining its magnitude among women beggars in such face to face interview was difficult even though, we have tried to minimize it. As any cross sectional study cause and effect relationship was not possible to establish for the factors dealt in the study for it is impossible which factor occur first (temporal relation-ship could not be assessed). The cross-sectional nature of the study may result in recall bias. This study touches on sensitive private matters in a setting where the issue under study faces social disapproval, thus the possibility of under reporting cannot be ruled out.

\section{Conclusions}

The current contraceptive use among women beggars in Bahir Dar town northwest Ethiopia is lower considering the natures of their life styles and living conditions. Being married women, education, currently living in rented houses, having discussion with HEWs, and history of sexual assault/rape were most likely to use modern contraceptive methods. Lack of modern contraceptive service 42 (35\%) was mentioned by a large number of women as a reason for not using modern contraceptives followed by want to have children $36(30 \%)$.

\section{Recommendation}

Based on the findings and the conclusions made, the following recommendations were forwarded.

FMOH should include those women beggars who live in a mass living room around church and mosque and on the street to include in the urban health extension program and in assigning HEWs to the main concentration areas.

Governmental and non-governmental NGO should give attention to those non-privileged groups of people to give interventions to the identified factors affecting modern contraceptive service use and do to create and increase awareness of beggar women about MCs use.

Health extension workers should enhance information, education and communication activities on modern contraception to all women beggars by including them in outreach activities and targets.

To Bahir Dar city administration for those women beggars who live in mass living rooms should give separate rooms for men and women which expose to sexual assault and rape.

Further research using qualitative or mixed approach would also be helpful in exploring barriers and perceptions about MCs service utilization among women beggar.

\section{Acknowledgements}

First of all praise be to GOD for his permission and assistance in the accomplishment of all works Of this paper, next I have realized fully that there are special people in certain situations whenever you are in need of their support and who can make your effort fruitfully by relating sufficiently and precisely the routine observations with acceptable scientific Explanations.

Next my deepest gratitude goes to my advisor Dr Fentie Ambaw (PhD) for their unreserved scientific guidance, constructive suggestions comments and willingness in helping and giving me invaluable idea from the very beginning.

I would like also to extend my heartfelt gratitude to data collectors, supervisors \& the study participants for their time and energy.

Last but not least I would like to acknowledge APHI, Bahir Dar city Health Bureau and Ministry Of Labour and Social Affairs of Bahir Dar city for their invaluable information and support.

\section{References}

[1] Foundation HJKF. the U.S. Government and International Family Planning \& Reproductive Health Efforts fact sheets factsheets. 2017: 8 .

[2] United Nations DoEaSA, Population Division World Population Prospects: The 2017 Revision, Key Findings and Advance Tables. Working Paper No. ESA/P/WP/248. UN population devision. 2017.

[3] ICF. CSACEa. Ethiopian Demographic and Health Survey 2016. Addis Ababa, Ethiopia, and Rockville, Maryland, USA: CSA and ICF. 2017; 3 (3): 551.

[4] Ahmed S, Li Q, Liu L, Tsui AO. Maternal deaths averted by contraceptive use: an analysis of 172 countries. The Lancet. 2012; 380 (9837): 111-25.

[5] Biniam Getachew ZB. Projection of Family Planning service in Ethiopia - 2011 to 2035. researchGate. 2015.

[6] HSTP. Federal Democratic Republic of ethiopia Ministry of Health, Health Sector Transformation Plan 2015/16-2019/20. HSTP 2015-2020. 2015: 184.

[7] Sourisseau J-M, Bougnoux N, Bélières J-F, Bourgeois R, Soumaré M, Rasolofo P. Envisioning the future of territories to tackle demographic and employment challenges in subSaharan Africa. Perspective-Cirad. 2017 (44).

[8] Wang H, Tesfaye R, Ramana GN, Chekagn CT. Ethiopia health extension program: an institutionalized community approach for universal health coverage: World Bank Publications; 2016.

[9] Hailu DM. Begging in a Fast Growing City: Trends and Situations in Bahir Dar City, Ethiopia. Research on Humanities and Social Science 2017; 7 (03): 16.

[10] Chimdessa A, Olayemi O, Akpa OM. Factors Associated with Vulnerability to HIV and Sexually Transmitted Infections among Street Children in Selected Towns of Ethiopia, 2016. World Journal of AIDS. 2017; 7 (03): 230.

[11] Guttmacher Institute AIU. Investing in Contraception and Maternal and Newborn Health,. factsheets. 2017.

[12] Groce N, Murray B, Kealy A. Disabled beggars in Addis Ababa: current situation and prospects for change. International Labour Office-Geneva: ILO. 2014. 
[13] Hailemariam A. Implementation of the Population Policy of Ethiopia: Achievements and Challenges. Population Horizons. 2016; 13 (1): 19-30.

[14] United Nations DoEaSAPD. Trends in Contraceptive Use Worldwide. UN population devision 2015: 70

[15] Sharan M, Ahmed S, May J, Soucat A. Family planning trends in Sub-Saharan Africa: progress, prospects, and lessons learned. Yes Africa Can. 2011: 445.

[16] ICF NSONMa. Malawi Demographic and Health Survey 2015-16. Zomba, Malawi, and Rockville, Maryland, USA NSO and ICF. 2017.

[17] Ministry of Health CD, Gender, Elderly and Children Tanzania, National Bureau of Statistics (NBS) OotC, Government Statistician (OCGS) aI. Tanzania Demographic and Health Survey and Malaria Indicator Survey (TDHS-MIS) 2015-16.. Dar es Salaam, Tanzania, and Rockville, Maryland, USA: MoHCDGEC, MoH, NBS, OCGS, and ICF. 2017.

[18] Envuladu E, Agbo H, Mohammed A, Chia L, Kigbu J, Zoakah A. Utilization of modern contraceptives among female traders in Jos South LGA of Plateau State, Nigeria. International Journal of Medicine and Biomedical Research. 2012; 1 (3): 224-31.

[19] Tuhin Roy MTK, Md. Tanvir Hossain and Sohel Rana. Reproductive health care seeking behavior of female street dwellers of Dhaka Metropolitan, Bangladesh. ResearchGate 2013; $11 \& ! 2$ (1).

[20] Stephen O. Kwankye PENCAT. Reproductive health implication of street hawking in Accra, Ghana International Journal of Academic Research in Education and Review. 2013.

[21] Shibihon Debebe M. Sc. MALMS, Belete Biadgo M. Sc. Modern contraceptive methods utilization and associated factors among reproductive aged women in rural Dembia District, northwest Ethiopia: Community based cross-sectional study. International Journal of Reproductive BioMedicine. 2017; 15 (06): 367-74.

[22] Feleke Gebremeskel, Dinkalem Getahun, Tesfaye Kanko. Prevalence of Modern Contraceptive Utilization and Associated Factors Among Women of Reproductive Age Group at Boditi Town, Wolayita Zone, SNNPR, Ethiopia. American Journal of Nursing Science. 2017; 06 (06): 447-53.

[23] Andualem Samuel, Abraham Uliso, Birke Olle, Desalech Dambe, and MN, Sorato MM. Assessment of Modern
Contraceptive Method Utilization and Associated Factors Among Women of Reproductive Age Group in Arba Minch Town, SNNPR, Ethiopia. Ec Gynaecology. 2017.

[24] Mahamed K, Medhanyie AA, Liben ML, Shamie R. Modern family planning methods utilization and associated factors among female students in Aysaita town, Northeastern Ethiopia. Medico Research Chronicles. 2017 (44): 411-9.

[25] Belda SS, Haile MT, Melku AT, Tololu AK. Modern contraceptive utilization and associated factors among married pastoralist women in Bale eco-region, Bale Zone, South East Ethiopia. BMC health services research. 2017; 17 (1): 194.

[26] Megabiaw B. Awareness and utilization of modern contraceptives among street women in North-West Ethiopia. BMC women's health. 2012; 12 (1): 31.

[27] Kaware AC, Kamble NH, Mangulikar SK. Prevalence of usage of different contraceptive methods among married women of reproductive age in an urban slum area. International Journal of Medical Science and Public Health 2017; 06 (1): 29-33.

[28] Ndayizigiye M, Fawzi MS, Lively CT, Ware N. Understanding low uptake of contraceptives in resourcelimited settings: a mixed-methods study in rural Burundi. BMC health services research. 2017; 17 (1): 209.

[29] Dias JG, de Oliveira IT. Multilevel effects of wealth on women's contraceptive use in Mozambique. PloS one. 2015; 10 (3): e0121758.

[30] Habtamu D, Adamu A. Assessment of sexual and reproductive health status of street children in Addis Ababa. Journal of sexually transmitted diseases. 2013; 2013.

[31] Misganaw AC, Worku YA. Assessment of sexual violence among street females in Bahir-Dar town, North West Ethiopia: a mixed method study. BMC public health. 2013; 13 (1): 825.

[32] Commission FDRoEPC. Summary and Statistical report of the 2007 population and housing census. Addis Ababa, Ethiopia. 2008.

[33] Gómez AM Sexual Violence as a Predictor of Unintended Pregnancy, Contraceptive Use and Unmet Need Among Female Youth in Colombia Journal of Women's Health 2017 20 (9), 1349-56.

[34] MOLSA. Ministry of Labour and Social Affairs of Bahir Dar Northwest Ethiopia Report MOLSA Report 2017. 